\section{Does Pulse Dosing of Methylprednisolone Have an Acute Effect on Serum Creatinine Concentrations?}

Pulse IV methylprednisolone therapy is the intermittent administration of supraphysiological quantities of the drug to enhance its therapeutic effects while reducing its toxic effects. ${ }^{1}$ A typical pulse regimen ranges from 500 to $1000 \mathrm{mg}$ IV daily for 2-4 consecutive days. ${ }^{1,2}$ It has been suggested that methylprednisolone may cause an acute increase in serum creatinine ( $\mathrm{SCr}$ ), which can be misinterpreted as a clinical indication of worsening renal function. ${ }^{3}$ A proposed mechanism for this effect is catabolic degeneration of protein and loss of muscle tissue induced by steroid therapy. ${ }^{3}$ However, the relation between pulse therapy and acute change in SCr after drug administration is not well defined. Sakemi and others ${ }^{4}$ conducted a retrospective analysis of 56 patients with renal or collagen disease receiving 3 consecutive pulses of methylprednisolone $1000 \mathrm{mg}$ IV daily. They found that the mean SCr increased significantly 1 day after the last dose and hypothesized that the observed effect depended on clinical status. ${ }^{4}$ They speculated that the increase in SCr could have been due to baseline nephrosis and renal impairment, as opposed to the drug therapy. Liu and others 5 conducted a prospective study involving 49 patients with collagen vascular disease who received methylprednisolone $1000 \mathrm{mg}$ IV daily for 3 consecutive days. In that study, there was no clinically significant change in SCr 1 day after the last dose. ${ }^{5}$ Other literature examining the relation between consecutive pulse doses of steroid and acute change in SCr after drug administration is limited, especially for patients without baseline renal impairment.

Characterizing the acute effects of pulse dosing of methylprednisolone on SCr has important benefits. It will assist clinicians in determining whether patients who experience an increase in SCr have renal impairment, as opposed to a transient increase caused by the medication, thus avoiding unnecessary diagnostic or corrective interventions.

A retrospective chart review was conducted for patients receiving pulse methylprednisolone for conditions in which renal impairment did not exist or was not anticipated from progression of disease at the time of treatment. All patients at 2 hospitals in Vancouver (St Paul's Hospital, a 500-bed tertiary care facility, and Mount Saint Joseph Hospital, a 100-bed community hospital) who received methylprednisolone 500-1000 mg IV daily for 2-4 consecutive days between July 1, 2009, and July 1, 2013, were considered for inclusion. The exclusion criteria were established renal impairment $(\mathrm{SCr}>110 \mu \mathrm{mol} / \mathrm{L}$ or estimated glomerular filtration rate $<50 \mathrm{~mL} / \mathrm{min}$ ) before the first dose of
Table 1. Characteristics of Study Participants

\begin{tabular}{|c|c|c|}
\hline \multirow{3}{*}{$\begin{array}{l}\text { Characteristic } \\
\begin{array}{l}\text { Age (years) (mean } \pm \text { SD) } \\
\text { Sex }\end{array}\end{array}$} & \multicolumn{2}{|c|}{$\begin{array}{c}\text { No. }(\%) \text { of } \\
\text { Participants* }(n=57)\end{array}$} \\
\hline & \multicolumn{2}{|c|}{$54 \pm 17$} \\
\hline & & \\
\hline Male & 26 & $(46)$ \\
\hline Female & 31 & $(54)$ \\
\hline \multicolumn{3}{|l|}{$\begin{array}{l}\text { Methylprednisolone, } \\
\text { total daily dose (mg) }\end{array}$} \\
\hline 500 & 15 & (26) \\
\hline 750 & 1 & $(2)$ \\
\hline 1000 & 41 & $(72)$ \\
\hline \multicolumn{3}{|l|}{ Duration of pulse dose (days) } \\
\hline 2 & 13 & $(23)$ \\
\hline 3 & 31 & (54) \\
\hline 4 & 13 & (23) \\
\hline \multicolumn{3}{|l|}{$\begin{array}{l}\text { Indication for pulse dosing } \\
\text { of methylprednisolone }\end{array}$} \\
\hline Vasculitis & 16 & $(28)$ \\
\hline Respiratory failure & 12 & $(21)$ \\
\hline Neuropathy & 6 & $(11)$ \\
\hline Encephalopathy or encephalomyelitis & 5 & (9) \\
\hline Myositis & 4 & (7) \\
\hline Rejection of heart transplant & 3 & (5) \\
\hline Glomerulonephritis & 3 & (5) \\
\hline Other & 8 & (14) \\
\hline
\end{tabular}

*Except where indicated otherwise.

methylprednisolone; shock requiring administration of vasoactive inotropes ${ }^{6}$; dehydration (negative fluid balance $>3 \mathrm{~L}$ between the pre- and post-methylprednisolone SCr measurements); receipt of dialysis or renal replacement therapy; or nephrotoxic medication (specifically, systemic aminoglycosides, IV acyclovir, or amphotericin B). ${ }^{7}$

Measurements of SCr concentration before and after methylprednisolone therapy were collected from the hospital patient care information system. For each patient, the pretherapy SCr value was a value recorded on the day of the first dose of methylprednisolone or, if unavailable for that day, the immediately preceding day. The post-therapy SCr value was a value recorded on the day after the last dose (e.g., day 4 if the patient had a 3-day regimen) or, if unavailable for that day, the next day. SCr concentrations for other days were not collected. The SCr measurements were summarized as means \pm standard deviations (SD). A 2-tailed paired $t$ test, for data with a normal distribution, was used to compare the means (using Microsoft Excel software; Microsoft, Redmond, Washington); $p$ values less than 0.05 were considered statistically significant. The study was approved by the University 
of British Columbia Clinical Research Ethics Board and the Fraser Health Authority Research Ethics Board.

A total of 57 eligible patients, for whom methylprednisolone was administered for various indications, were identified (Table 1). Pulse methylprednisolone therapy had no statistically significant acute effect on SCr: mean SCr was $68 \pm 21 \mu \mathrm{mol} / \mathrm{L}$ before therapy and $68 \pm 30 \mu \mathrm{mol} / \mathrm{L}$ after therapy $(p=0.98)$.

This retrospective study of pulse methylprednisolone dosing for conditions in which renal impairment did not and was not anticipated to exist provides support that this drug has no apparent acute effect on SCr. Although the study design was limited by its retrospective nature and assumptions that documentation of exclusion criteria was complete and that $\mathrm{SCr}$ was assessed immediately after completion of therapy, the results suggest that this regimen has no acute effect. Turner and others ${ }^{8}$ reported an increase in SCr 7 days after a dose of methylprednisolone $10 \mathrm{mg} / \mathrm{kg}$ IV in patients undergoing elective open repair of abdominal aortic aneurysm. It is possible that a significant increase occurred 2 days after the last dose, but the study was not designed to assess that timing.

Clinicians using pulse dosing of methylprednisolone for 2-4 days should not anticipate any change in SCr over this duration of therapy. As such, routine measurement of $\mathrm{SCr}$ to assess the potential renal toxicity of methylprednisolone is not warranted. If patients experience acute changes in $\mathrm{SCr}$ while receiving pulse IV methylprednisolone therapy, investigations for other causes should be conducted, as such changes are unlikely to be due to this medication.

\section{References}

1. Pasrichia JS. Pulse therapy as a cure for autoimmune diseases. Indian J Dermatol Venereol Leprol. 2003;69(5):323-8.

2. Then Bergh F, Kümpfel T, Schumann E, Held U, Schwan M, Blazevic M, et al. Monthly intravenous methylprednisolone in relapsing-remitting multiple sclerosis-reduction of enhancing lesions, T2 lesion volume and plasma prolactin concentrations. BMC Neurol. 2006;6:19.

3. Andreev E, Koopman M, Arisz L. A rise in plasma creatinine that is not a sign of renal failure: which drugs can be responsible? J Intern Med. 1999;246(3):247-52.

4. Sakemi T, Fujimoto S, Fujimi S, Yamamoto Y, Etoh T, Yamaguchi M. Transient renal failure following intravenous methylprednisolone pulse therapy. Curr Ther Res. 1992;52(2):254-64.

5. Liu CH, Hsieh SC, Wu CH, Yu CL. Effects of the methylprednisolone pulse therapy on renal function. Formosan J Rheumatol. 2007;21:6-12.

6. Graham CA, Parke TRJ. Critical care in the emergency department: shock and circulatory support. Emerg Med J. 2005;22(1):17-21.

7. Guo X, Nzerue C. How to prevent, recognize, and treat drug-induced nephrotoxicity. Cleve Clin J Med. 2002;69(4):289-90, 293-4, 296-7 passim.

8. Turner S, Derham C, Orsi NM, Bosomworth M, Bellamy MC, Howell SJ. Randomized clinical trial of the effects of methylprednisolone on renal function after major vascular surgery. Br J Surg. 2008;95(1):50-6.

Eric C Wong, BSc(Pharm), ACPR

Pharmacy Practice Resident, 2013/2014

Lower Mainland Pharmacy Services

Vancouver, British Columbia

Glen Brown, BSc(Pharm), PharmD, FCSHP, BCPS

Pharmacy Department

St Paul's Hospital

Vancouver, British Columbia

Glen Brown is also an Associate Editor with the CJHP.

Competing interests: None declared.

\section{ON THE FRONT COVER}

\section{Formal Garden, Assiniboine Park, Winnipeg, Manitoba}

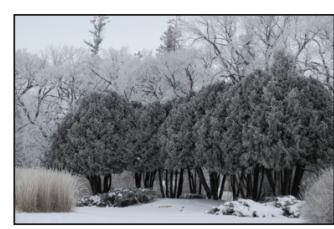

CSHP member Donna Woloschuk (Regional Pharmacy Manager, Educational Services, Winnipeg Regional Health Authority) describes this issue's cover photograph in her own words: "I snapped this photo on December 15, 2012, with a Nikon Coolpix P7000 (automatic) camera, while cross-country skiing in the Formal Garden at Assiniboine Park, Winnipeg, Manitoba. I had headed out early in the morning, hoping to find this part of the park undisturbed. The contrast in temperature between overnight $\left(-18^{\circ} \mathrm{C}\right.$ to $\left.-25^{\circ} \mathrm{C}\right)$ and daytime $\left(-4^{\circ} \mathrm{C}\right.$ to $\left.-6^{\circ} \mathrm{C}\right)$, combined with about $6 \mathrm{~cm}$ of new snow that had fallen over the preceding 3 days, created ideal conditions for hoarfrost, which highlighted the beauty of the park's plantings and 110-year-old cedars and other trees. I skied as close as possible to the opposing hedgerow to preserve the pristine condition of the new snow. This shot is memorable because it was taken at a $90^{\circ}$ angle to the direction of my skis (which had sunk about a foot below the surface of the snow, boots and body attached!)." Read more about Assiniboine Park at: http://assiniboinepark.ca/about/

The CJHP would be pleased to consider photographs featuring Canadian scenery taken by CSHP members for use on the front cover of the journal. If you would like to submit a photograph, please send an electronic copy (minimum resolution $300 \mathrm{dpi}$ ) to cjhpedit@cshp.ca. 